\title{
OH signature of pyroxenes: A new probe for studying lithospheric processes?

\author{
JANNICK INGRIN
}

Univ. Lille, CNRS, INRAE, ENSCL, UMR 8207 - UMET -

Unité Matériaux et Transformations

Presenting Author: jannick.ingrin@univ-lille.fr

Depending of their metasomatic history or geodynamic origin $\mathrm{OH}$ stretching bands of lithospheric pyroxenes in the frequency range $3000-3700 \mathrm{~cm}^{-1}$ show different signatures. Pyroxenes from continental lithosphere having undergone "wet" metasomatism have distinct signature compared to continental pyroxenes having undergone "dry" metasomatism. Pyroxenes from oceanic lithosphere have a third type of signature. We present recent analyses of xenoliths and a review of the literature showing that the phenomenon is widely distributed among continents and oceans. It shows that the phenomenon affects simultaneously opx and cpx and pyroxenes from various lithologies: peridotites, pyroxenites and granulites. For instance, in continental lithosphere, $\mathrm{OH}$ bands at 3600 and $3415 \mathrm{~cm}^{-1}$ for opx and 3635 and $3445 \mathrm{~cm}^{-1}$ for cpx dominate pyroxenes affected by "wet" metasomatism; while $\mathrm{OH}$ bands at 3570 and $3515 \mathrm{~cm}^{-1}$ for opx and 3595 and $3515 \mathrm{~cm}^{-1}$ for cpx dominate pyroxenes affected by "dry" metasomatism. Opxs from oceanic lithosphere have $\mathrm{OH}$ spectra dominated by the band at $3415 \mathrm{~cm}^{-1}$ with a smaller contribution of the bands at 3520 and $3570 \mathrm{~cm}^{-1}$.

In all these observations it was not possible to correlate the signatures with a specific major, minor or trace element and the exact nature of the signatures remains to be identified. Nevertheless, these $\mathrm{OH}$ signatures are representative of specific lithospheric events and offer a potential new benchmark for the study of lithospheric processes. 